\title{
Cultural Issues in Medical Tourism
}

\author{
I-Chun Liu ${ }^{1}$ and Chii-ching Chen ${ }^{2}$ \\ ${ }^{I}$ Department of Social and Policy Sciences, Yuan Ze University, Taiwan \\ ${ }^{2}$ Department of Public Affairs and Management, Kan Nan University, Taiwan
}

\begin{abstract}
Medical tourism has become an emerging industry in recent years. Both developed and developing countries are involved in this field. For example, British patients seem to prefer India for medical tourism services. American medical tourists always fly to Mexico to receive medical care, in order to reduce culture shock. This means that medical services include the consideration of cultural familiar. The research objectives of this paper include (1) discussing the relevant research and literature concerning the relationship between culture and medical services; (2) analyzing the relationship between culture and medical tourism; and (3) proposing policy advice to the government for promoting medical tourism services, based on the discoveries of previous research. The research employs secondary data collected from the relevant literature. Our main contribution is the provision of a review of the impact of cultural competency on medical tourism services. Another contribution of this study is that its findings can serve as a reference for further empirical analysis. We find that cultural competence should be integrated into healthcare systems, medical organizations, and individuals. These findings show that countries providing medical tourism services should examine physician-patient communication methods and physicianvisitor culture, because each may lack sufficient cultural competence, as well as levels of cultural respect. It is recommended that healthcare providers arrange for such education for their employees; a small booklet or video demonstration can do wonders in this regard.
\end{abstract}

Keywords: Medical service, medical tourism, culture, cultural competency

\section{Introduction}

Today, there is great receptiveness towards medical tourism. Discussions regarding the formation of the medical tourism industry are commonly analyzed from a market perspective. For the demand side, patients in Europe and the United States are unable to afford the high medical expenses in their countries or encounter long waiting periods for treatment. For the supply side, medical service providing countries are able to provide high-quality and low-cost medical services.

Medical services are a part of social infrastructure. Therefore, they are viewed not only as market commodities but also as something with culturerelated aspects that are difficult to alter (Berger \& Luckman, 1966). Medical services are viewed not only as market commodities but also as something with cultural aspects that are difficult to alter. Once a medical tourist has traveled to a foreign country for care, he or she may face the risk of miscommunication resulting from a lack of familiarity with a foreign culture and language barriers (Yanos, 2008). There is a great need for overall cultural understanding in medical tourism and healthcare.

Medical tourism has become an emerging industry in recent years, and both advanced and developing countries are involved in this field. For example, British patients seem to prefer India for medical tourism services. American medical tourists always fly to Mexico to receive medical care, in order to reduce culture shock. This means that medical services include the consideration of cultural familiar. The research objectives of this paper include (1) discussing the relevant research and literature concerning the relationship between culture and medical services; (2) analyzing the relationship between culture and medical tourism; and (3) proposing policy advice to the government for promoting medical tourism services, based on the discoveries of previous research. The research employs secondary data collected from the relevant literature.

This paper attempts to analyze the relationships between medical tourism services and culture in the emergent medical tourism industry with a secondary data analysis method. This research collected literature concerning culture competency, medical services, and medical tourism services. According to research on the medical tourism market, global standards in medical technology and fiercely competitive market prices result in the culture or cultural competence of medical tourists playing an invisible, but influential, role. 


\section{An Analysis of Culture and Medical Services}

Personnel in the medical care field understand the importance of cultural competence; however, they have not established a collectively accepted definition of the concept. Culture is regarded as a method of living that is accumulated and adapted by a social group; it includes all non-genetic group adaptive behavior. Researchers use terms like cultural appropriateness, cultural sensitivity, cultural belief, and cultural knowledge and ability to illustrate the idea. These terms contain the same essential elements, including cultural value diversity, cultural selfassessment ability, consciousness of cultural dynamics, and demonstration and adjustment of cultural knowledge.

Discussion of the medical and cultural relations is not a new thing. Early work in medical sociology has discussed this topic and also progressing in empirical studies. Culture can be described as the interplay of many elements which including behaviors, customs, beliefs, values and institutions (Mays, Siantz \& Viehweg, 2002).

In a society with advanced medical science and technology, the medical care system led by Western medical practitioners often focuses on the treatment of diseases. Patients accept medical professionals' possession and exercise of power without debate, and patients' cultural, social, and economic factors are neglected. Currently, consumers are exposed to different cultures; they develop new ideas and cultivate modern viewpoints. They have multiple demands, often borrowed from other cultures, seasoned with personal beliefs. The new self-sufficient consumer has become more individualistic and requires more customized and highly developed services, with greater choice, quality, variety, and good value. Consumers truly have become global; their demands have multiplied because of broad cultural exposure (Jagyasi, 2010). In the past, the requirement has been limited to cultural diversity within one geographic region, because most patients came from one region with different cultures and beliefs. As a result of developments in communication tools, information technology, and increased social media exchanges, they have been exposed to different cultures and developed new ideas and viewpoints.

When patients travel overseas for medical treatment, there is an emergence of new consumers, and they show a completely different behavior pattern. In choosing a country for health services, medical tourists are concerned about the quality of medical care and the market price; personal cultural values, preferences, or habits also factor into medical treatment decisions. It is very common for the British to travel to India for medical tourism; however, for
Americans, receiving medical treatment in India brings greater culture shock than receiving treatment in Mexico (Ferguson \& Candib, 2002: 357-360). The Japanese prefer to seek medical treatment in Taiwan instead of Southeast Asian countries; people from mainland China feel more secure and at ease when seeking medical treatment in Taiwan.

Another factor influencing the Western emphasis on cultural issues is the broad focus on patientcentered ideas and cultural competence. Patientcentered ideas entail providing personalized medical care for patients and emphasizing individual physician-patient relationships. The concept stresses that every patient should be treated fairly and that medical service providers must understand every patient's preferences and needs. An understanding of individual needs based on religion, ethnicity, or geography might not be necessary in every case, but this will certainly bring higher satisfaction. Also, the comfort of a patient plays an important role in the efficiency of their treatment. Patient-centered ideas and cultural competence complement each other and employ different methods to serve the same purpose. For example, in recent years, large hospitals have run "elderly clinics" or "elderly outpatient" services for persons over the age of 65 , in order to provide integrated medical treatment. Physicians have ample time for interrogation to understand the elderly patient and the physical and mental aspects of their condition and are aware of potential problems and morbidity, thus providing an overall treatment plan and healthcare services that meet their needs. Such complex needs require customized solutions. There should be a comprehensive system in place to educate patients as well as healthcare providers about cultural beliefs, dissimilarities, and needs.

Understanding culture in medical services is a two-way process, where providers need to understand patients' cultural beliefs and behaviors, and patients also need to understand the culture and behavior of the provider country. Both healthcare providers and healthcare consumers need to understand cultural dissimilarity (Jagyasi, 2010). The widely discussed concept of cultural competence refers to consistent modes of behavior, attitude, and policy that exist among institutions or experts, enabling them to work more effectively within cross-cultural situations. On an individual level, cultural competence involves developing empathy and related knowledge, an understanding that the world is composed of diverse cultures, and the ability to interact with a complex world from another perspective. Language competence is often mentioned together with cultural competence in the medical field. Cultural and language competence are widely regarded as important aspects in enhancing medical quality. If 
medical service providers do not share the same language with their patients, misdiagnoses and inappropriate treatment may occur. If patients share the same language with medical service providers, they are more satisfied with the services provided and they establish a relationship of mutual respect with providers, increasing the efficacy of physician-patient communication (Goode et al., 2006: 1). Medical service providers with cultural competence can manage services for patients with different values, conduct self-assessment for cultural competence, manage diverse cultural dynamics, and adapt to different diverse cultures and service group cultural environments. For example, medical service providers can understand the communities in which their patients live as well as the health beliefs of their patients and their daily behaviors, and attempt to understand cultural factors and their interactions with the medical care system. The cultural competence of medical personnel is also known as clinical cultural competence (Anderson et al., 2003: 68). Cultural competence focuses on care for people of different ethnicities and comparatively disadvantaged groups. When medical professionals provide individualized medical care, physicians consider the differences between patients of varying cultures and provide customized services based on their cultural competence. Cultural competence is also employed to finally transform medical care into individual patientcentered care (Beach et al., 2006: 1). Cultural competence is both a vehicle to increase access to quality care for all patient populations and a business strategy to attract new patients and market share (Betancourt et al., 2002).

In simple language, cultural diversity can be understood in many different ways. It is often referred to as the mixture of different human groups, societies, or cultures in a specific place. Diversity can also mean differences in race, ethnicity, nationality, religion, or language among various groups within a community, organization, or nation. Individual values, beliefs, customs, traditions, and backgrounds also bring cultural diversity (Jagyasi, 2010). Through training and education, the awareness of medical providers - including their awareness of how sociocultural factors influence beliefs and behaviorcan be increased. Providers can also keep in mind the influence that race, ethnic group, and culture have on clinical decision-making. In addition to individual clinical cultural competence, cultural competence in the medical field can be divided into different types. One is organizational cultural competence, which can increase the diversity of the healthcare labor force and leadership ability and includes board-composed, personnel-composed, and human resources management differentiation (Procter, 2003). Another is cultural competence for the healthcare system, which implements a cultural competence assessment in a community and develops feedback mechanisms, conducts competence for race and language preferences, and monitors the patient satisfaction level for different races and ethnicities. Increasing cultural competence methods in the healthcare system includes gaining support from high levels of management, including cultural competence in the major work performance indicators, or integration with different levels of cultural competence (Goode $\&$ Jones, 2004).

Cultural competence is not a panacea for improving health results and eliminating inequality; however, it is a necessary condition for providing patients superior care quality. Based on the overall impact of culture on healthcare systems, the life habits and local customs adopted by different cultural backgrounds often lead to the occurrence or prevalence of regionally specific diseases (Beach et al., 2006: 5). In different societies molded by different cultures, people possess significantly different understandings and concepts of diseases, and even develop conflicting and contradictory ideas. Different societies' understandings of diseases demonstrate cultural differences, and people display different aspects or appearances of help-seeking behavior when encountering disease. Different cultural groups will display significant differences in social reactions and support systems. Other overall cultural impacts on the healthcare field include body culture, which emphasizes body subjectivity, and cultures that emphasize patient privacy. If these cultural factors are applied to hospitalization care, we can observe that, for dietary culture, red beans are considered a dessert in Eastern dietary culture, whereas they are viewed as a vegetable in Western society. Furthermore, different religions will also have various taboos for food. For example, patients from the Middle East will have special preferences for food and drink.

Cultural competence provides advantages for healthcare. It helps people from different races and ethnic groups and those possessing different cultural characteristics achieve equality and fairness in medical treatment, promotes the health knowledge and ability of consumers, and reduces delays when patients of different cultures seek medical services. Moreover, it encourages the interaction and communication between medical service consumers and providers. In this way, patients become more willing to accept physician-suggested treatment, and negligence and side effects for physician treatment are reduced (Cicourel, 1982). This facilitates the execution of follow-up treatment, reduces preventive hospitalization occurrence rates, and promotes 
consumer service satisfaction levels and medical safety (Papps \& Ramsden, 1996).

For example, hospitals have successively begun outpatient practices and services for the elderly. They provide elderly people over 65 years of age with integrated medical treatment and allow physicians to have sufficient time for inquiry to understand elderly patients' physical and mental illness conditions, discover potential problems, and provide healthcare services that fulfill requirements.

\section{An Analysis of Relationship between Culture and Medical Tourism}

The relationship between tourism and culture is increasingly emphasized. Two different approaches discuss the impact of culture on tourism, and the impact of cultural competency on the provision of tourism services. With regard to the first, culture and creative industries are increasingly collaborating to promote destinations and enhance their competitiveness and attractiveness. Many locations are now actively developing their tangible and intangible cultural assets as a means of developing comparative advantages in an increasingly competitive tourism marketplace and also to create local distinctiveness in the face of globalization. The impact of culture on tourism examines the growing relationship between tourism services and culture, and the way in which they have together become major drivers of destination attractiveness and competitiveness. Relevant publication shows how a strong link between tourism and culture can be fostered to help locations become more attractive to tourists, as well as to increase their competitiveness as locations to live, visit, work, and invest in.

The other approach is the core consideration of this paper. Medical tourists are at the center of the medical tourism system and thus exert considerable influence on it. Studies on the demographics of medical tourists are currently being actively pursued. One aspect that the medical tourism industry must focus on is the behavior and market preference of medical tourists. These tourists are especially vulnerable as they are unfamiliar with their surroundings and are weakened both physically and mentally, thus requiring higher levels of attention and protection (Caffarini, 2008). Other factors also contribute to the increasing numbers of medical tourists. As Garcia-Altes (2005) points out, medical tourism is most accessible to the baby boom generation, which has the highest income rates and the highest tendencies to take vacations. They are less sensitive to price and are more interested in various factors such as destination, quality, and secrecy that make up marketing strategies. Finally, the cultural attitude of the local population towards foreigners is also an important factor in medical tourists' choice.

In specific instances, such as during the month of Ramadan, Muslims prefer to fast and not to consume any oral medications. Food services, for example all catering staff, should be aware that only halal meat must be given to Muslim patients. With regard to clinical or nursing care, it is, for example, preferable for a female Muslim to be cared for by women and a male Muslim by men. This is most important during confinement when strict privacy is essential. According to media reports, the number of tourists visiting Taiwan from mainland China has increased, and most tour groups are composed primarily of elderly tourists. Elderly tourists cannot move as rapidly, nor can they execute actions in as agile a manner as younger people. In addition, related infrastructures in scenic areas, reception personnel, transportation arrangements, and hotel accommodations do not specifically consider the needs of the elderly. Furthermore, when tourists travel to unfamiliar environments, they face challenges to their bodies and minds. Without proper planning, elderly tourists are more susceptible to accidents, resulting in a decrease in travel quality.

The market for medical tourism includes not only high-quality healthcare for the physical wellbeing of international patients, but also includes impacts to mental emotions and sociocultural dimensions. Medical tourists consider individual cultural values, preferences, or habits when choosing medical services in other countries. When they arrive in unfamiliar environments, tourists create challenges for their bodies and minds. Specifically, ill tourists are more sensitive to environmental factors, and must overcome mental barriers to nakedly and openly present themselves to foreign medical personnel for treatment.

When analyzing the relationship between culture and medical tourism with regard to the requirements of the medical tourism market, it can be determined that international patients have more rights and opportunities to actively choose physicians compared to when they seek medical treatment domestically. When patients consider receiving medical services in foreign countries and presenting their bodies and health for treatment by foreign physicians, they must consider price, medical technology, and tourism. Apart from those factors, cultural thinking and ideas are also crucial, including language ability or competence for physician-patient communication, respect for patient privacy, respect for subjectivity of the body, cultural dietary requirements, and the physician-visiting culture. International healthcare organizations make efforts to educate their staff about 
understanding the cultural dissimilarity of international patients. They teach providers about key cultural challenges arising from geographies, languages, religion, societies, beliefs, customs, traditions, and individual perceptions (Jagyasi, 2010). The ultimate objectives of cultural understanding in medical tourism are to create better outcomes that minimize gaps, understand and build awareness of applications, avoid any miscommunication or misunderstanding arising from cultural disbeliefs, and provide more positive results with a higher satisfaction rate. Such processes require meticulous understanding about the impacts cultural disbelief could have on a healthcare practice and also the understanding of patient needs and delivery of healthcare services. In a relevant empirical study, Yu and Ko (2012) observe factors related to perceptions of, and possible participation in, medical tourism by Chinese, Japanese, and Korean visitors to Jeju Island in Korea. The study describes distinct characteristics of medical tourism of the three cultural groups. The differences among Chinese, Japanese, and Korean tourists with regard to the selection of destination, inconveniences, and preferred products were all found to be significant. Korean tourists placed most significance on selection factors, followed by Chinese tourists, and, lastly, by the Japanese. On the other hand, inconveniences related to medical and care services, stay and cost, and information and insurance elements were most strongly associated with Japanese tourists. This may be a reflection of a possible tendency of Japanese tourists to value safety and cost effectiveness. For Chinese tourists, the importance of stay and cost was equally high as those of their Japanese counterparts, which is indicative of Chinese tourists' cost sensitivity. Light treatments (minor surgery) were preferred by Chinese tourists, while more significant treatments (major surgery) were preferred by Japanese tourists.

\section{Contributions, Limitations and Future Research Directions}

A key contribution of this research is that it provides a systematic literature review of the impact of cultural competency on medical tourism services. Another contribution of this study is that its findings can serve as a reference for further empirical analysis. In addition, several future research directions emerged from this study. A major weakness is that this paper mainly utilized the literature review method. Other limitations of this paper are as follows. First, the paper employed does not present a description of related data, which means that more cross-country comparison between different medical tourists is needed. Second, this paper does not include details of different types of medical tourism services (for example diagnostics and check-ups, cardiology/cardiac surgery, fertility/reproductive system, cosmetic surgery organs, and cell and tissue transplantation). There is much potential for future studies using this model, for example, studies on the relationship between the cultural competency of different types of medical tourists and the medical tourism industry, or on those who develop marketing strategies according to target market or consumer groups.

\section{Conclusion}

Globalization across all sectors has brought complex cultural needs, in an already culturally diverse world. Understanding culture and behavior was important in healthcare to provide comprehensive care with a delightful experience, but it has certainly become essential in medical tourism as patients arrive with different cultural beliefs and from different geographies. Cultural competence can be discussed further in terms of healthcare systems, medical organizations, and individual levels. From the dimension of medical service supply, how to increase cultural competence and respect for diverse cultural values among systems, organizations, and individuals should be taken as a target for further diligence.

Unlike the procurement of medical equipment, increasing understanding, recognition, and respect for foreign cultures and different people or ethnicities cannot be achieved in a short period of time. Creating bilingual or multilingual indications in environments, or arranging translation services, is not equivalent to demonstrating cultural competence. Therefore, cultural competence should be integrated through healthcare systems, medical organizations, and individuals. This includes the fact that increasing cultural competence and respect for diverse cultural values among systems, organizations, and individuals should be an important objective for medical service suppliers. Specifically, in order to understand, recognize, and respect a foreign culture, people, or ethnicities, cultivation and training are imperative. Besides promoting high-quality and inexpensive medical technology and prices, in order to attract more medical tourists, countries providing medical tourism services should examine physician-patient communication methods and physician-visitation culture, which may lacks sufficient cultural competence, as well as levels of cultural respect for foreign peoples or ethnicities. Healthcare providers should arrange for such education for their patients; a small booklet or video demonstration can do wonders in this regard. This will eventually result in comprehensive solutions for issues that arise from cultural differences. 


\section{References}

Anderson, L. M., S. C. Scrimshaw, M. T. Fullilove, J. E. Fielding \& J. Normand (2003). Culturally competent healthcare systems: A systematic review, American Journal of Preventive Medicine, 24 (3, Supplement 1), 68-79.

Beach, Mary Catherine, Somnth Saha, \& Lisa A. Cooper (2006). The role and relationship of cultural competence and patientcenteredness in health care quality, The Commonwealth Fund, October 2006.

Berger, Peter L. \& Thomas Luckmann (1966). The social construction of reality: A treatise its the sociology of knowledge. New York: Anchor Books.

Betancourt, J. R., A. R. Green, \& J. E. Carrillo (2002), Cultural competence in health care: emerging frameworks and practical approaches. New York: The Commonwealth Fund.

Caffarini, K. (2008). AMA meeting: Guidelines target safety of medical tourists, American Medical News, July 7. Retrieved from: http://amaassn.org/amednews/2008/07/07/prse07 07.htm

Cicourel, Aaron V. (1982). Language and belief in a medical setting, in H. Burnes (ed.) Contemporary perceptions of language: Interdisciplinary dimensions, Washington: Georgetown University Press, 48-78.

Ferguson, Warren J. \& Lucy M. Candib (2002). Culture, language, and the doctor-patient relationship, Family Medicine, 34(5), 353-361.

Garcia-Altes, M. (2005). The development of health tourism services, Annals of Tourism Research, 32(1), 262-266.
Goode T \& W. Jones (2004). Definition of linguistic competence, Washington, D.C: National Center for Cultural Competence, Georgetown University Center for Child and Human Development.

Goode, Tawara D., M. Clare Dunne, \& Suzanne M. Bronheim (2006). The evidence base for cultural and linguistic competency in health care, The Commonwealth Fund, October 2006. Retrieved from: www.cmwf.org.

Jagyasi, Prem (2010). Medical tourism impact It's more than Obvious. Retrieved from: http://www.medicaltourismmag. com/article/medical-tourism-impact-it-s-more-than-obvious. html

Mays, R, M. Siantz, and S. Viehweg (2002). Assessing cultural competence of policy organizations, Journal of Transcultural Nursing, 13(2), 139-144.

Papps, E. \& I. Ramsden (1996). Cultural safety in nursing: the New Zealand experience, International Journal for Quality in Health Care, 8(5), 491-497.

Procter, C. (2003). Blended learning in practice. Paper presented at education in a changing environment, University of Salford,

Yanos, Melana (2008). Medical tourism: Seeking affordable healthcare overseas, Retrieved from: http://www.nuwireinvestor.com/articles/medical-tourismseeking-affordable-healthcare-over seas-51469.aspx.

Yu, Ji Yun \& Tae Gyou Ko (2012). A cross-cultural study of perceptions of medical tourism among Chinese, Japanese and Korean tourists in Korea, Tourism Management, 33(1), $80-88$ 